\title{
Inhibition Effect of Nevirapine an Antiretroviral on the Corrosion of Mild Steel Under Acidic Condition
}

\author{
J. Ishwara Bhat* and Vijaya D. P. Alva ${ }^{\dagger}$ \\ Department of Chemistry, Mangalore University, Mangalagangotri, Karnataka, India. *E-mail: bhatij@yahoo.com \\ 'Department of Chemistry, Shree Devi Institute of Technology, Karnataka, India
}

(Received July 19, 2011; Accepted August 25, 2011)

\begin{abstract}
Corrosion inhibition of mild steel by nevirapine, an antiretroviral has been investigated using potentiodynamic polarization, electrochemical impedance spectroscopy technique and weight loss methods. The experimental results suggested, nevirapine is a good corrosion inhibitor for mild steel in $1 \mathrm{M}$ hydrochloric acid medium and the inhibition efficiency increased with increase in inhibitor concentration. The kinetic parameters for corrosion process and thermodynamic parameters for adsorption process were calculated and discussed. The adsorption of the inhibitor on the surface of mild steel followed Langmuir adsorption isotherm.
\end{abstract}

Key words: Mild steel, Weight loss, Polarisation, EIS, Acid corrosion

\section{INTRODUCTION}

Corrosion of metals is a major industrial problem that has attracted many investigators and researchers. Due to general aggressiveness of acid solutions, respective materials of constructions are getting corroded easily. Development of methods to control such corrosion is a challenge to chemists and scientists, working in this area. A large number of methods have been employed to understand the practical problem and its control.

Inhibition is one of the most important applications in the corrosion protection. The use of specific chemical compound as an inhibitor is the best, simple and practical method to minimize corrosion of metals. The corrosion inhibitors bring down the rate of corrosion to a greater extent, even when added in small quantities to the corrosive environment. Inhibitors protect the metals by getting adsorbed on to the surface of it effectively, blocking the active sites of metal dissolution and/or hydrogen evolution, thus retarding overall metal corrosion in aggressive environment. Organic molecules could be adsorbed on the metal surface by one of the following four mechanisms (a) electrostatic interaction between charged surface of the metal and the charge of the inhibitor (b) interaction of unshared electron pairs in the inhibitor molecule with the metal (c) interaction of $\pi$ electron with the metal and (d) a combination of the (a-c) types. Selecting an appropriate inhibitor for a specific environment and the corroding metal is of great importance, since an inhibitor that protects one particular metal may accelerate the cor- rosion of other.

A large number of organic compounds are known to be applicable as corrosion inhibitors for metals. ${ }^{1-11}$ Although existing data show that many organic inhibitors have good anti corrosive ability, some of them are highly toxic to both human beings and environment. The safety and environmental issues of corrosion inhibitors arisen in industries has always been a global concern. Use of environmental friendly pharmaceutical compounds as corrosion inhibitors has been reported by only a few investigators. ${ }^{12-15}$ Hence there is a need for an extensive investigation on eco-friendly pharmaceutical compounds which can be used as corrosion inhibitors.

Nevirapine (Fig. 1) is a non-nucleoside reverse transcriptase inhibitor (NNRTI) class of antiretrovirals used for the treatment of HIV-1 infections and AIDS. Neviraprine is structurally a member of dipyridodiazepinonechemical class of compounds. ${ }^{16,17}$ The IUPAC name of Nevirapine is 11-cyclopropyl-4-methyl-5,11-dihydro-6Hdipyrido[3,2-b:2,3-e][1,4]diazepin-6-one. The presence of

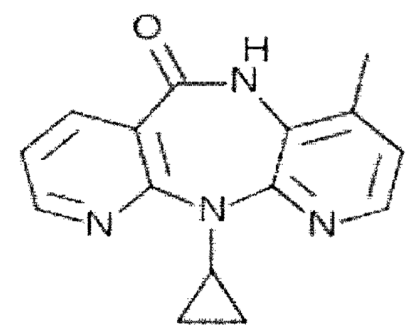

Fig. 1. Molecular structure of Nevirapine. 
electron rich $\mathrm{N}$ atoms and $\pi$ - bonds in its structure might be in favour of its adsorption on the metal surface which gives a scope for its study as a potential corrosion inhibitor. Perusals of several literatures reveal that, there is no information regarding the use of nevirapine as corrosion inhibitor for mild steel. The aim of the present investigation is to study the effect of nevirapine as a potential inhibitor for mild steel in $1 \mathrm{M} \mathrm{HCl}$.

\section{EXPERIMENTAL}

The specimens used were mild steel samples with chemical composition-(wt $\%)$ : C $(0.18 \%), \mathrm{Mn}(0.6 \%), \mathrm{S}$ (0.05\%), P (0.04\%), Si (0.1\%) and Fe (balance). Test materials were abraded with different emery papers up to 1000 grade, cleaned with acetone, washed with double distilled water and properly dried prior to exposure. Analar grade $\mathrm{HCl}$ and double distilled water were used to prepare all the solutions. Nevirapine (F.W. 266.3) from Frapps Chemical Reagent Co. Ltd was used for the study.

Weight loss measurements were performed on mild steel coupons with dimensions $1 \times 0.3 \times 0.06$ in $1 \mathrm{M}$ hydrochloric acid solution with different concentrations of the inhibitor. Weight loss of the metal coupons was noted after an immersing period of 24 hours at the temperature range from $303 \mathrm{~K}$ to $333 \mathrm{~K}$. Experiments were carried out in triplicate to get good reproducibility.

Electrochemical tests were carried out with a $\mathrm{CH}$-analyzer model-CH1660D. The cell arrangement used was a conventional three electrode cell with platinum counter electrode, saturated calomel electrode as reference electrode and test material (mild steel) as working electrode. The test material was covered by epoxy adhesive-araldite, so that only $1 \mathrm{~cm}^{2}$ area was in contact with the solution. Polarization curves were recorded potentiodynamically, at the scan rate of $1 \mathrm{mV} / \mathrm{s}$, in the range of $+250 \mathrm{mV}$ to $-250 \mathrm{mV}$ versus OCP potential. Impedance was measured over a frequency range of $1 \mathrm{M} \mathrm{Hz}$ to $0.05 \mathrm{~Hz}$ using amplitude of $10 \mathrm{mV}$ peak to peak AC signal.

\section{RESULTS AND DISCUSSION}

\section{Polarization measurements}

Polarisation measurements were carried out to obtain Tafel plots in the absence and presence of various concentrations of the inhibitor. The values of electrochemical parameters obtained from Tafel plots such as corrosion rate $\left(C_{R}\right)$, corrosion potential $\left(E_{\text {corr }}\right)$, current density $\left(i_{\text {corr }}\right)$, cathodic and anodic Tafel slopes ( $\beta \mathrm{c}$ and $\beta \mathrm{a}$ ) and inhibition efficiency (I.E \%) are given in Table 1. The inhibition efficiency (I.E \%) was calculated using equation (1) as given below, ${ }^{18}$

$$
\mathrm{I} . \mathrm{E}(\%)=\left(1-\frac{i_{\text {corr }}^{\prime}}{i_{\text {corr }}}\right) \times 100
$$

where, $i_{\text {corr }}^{\prime}$ and $i_{\text {corr }}$ are the corrosion currents in the presence and absence of the inhibitor respectively.

Fig. 2 shows the potentiodynamic polarisation curves for mild steel in $1 \mathrm{M} \mathrm{HCl}$ containing 0, 5, 10, 50, $100 \mathrm{ppm}$ of nevirapine at $303 \mathrm{~K}$. Corrosion current $\left(i_{\text {corr }}\right)$ was found to decrease with increase in inhibitor concentration indicating, the increased inhibition efficiency with the increase in the concentration of the inhibitor. In acidic solution the anodic process of corrosion is the passage of metal ions from the solid metal to the solution, and the principal

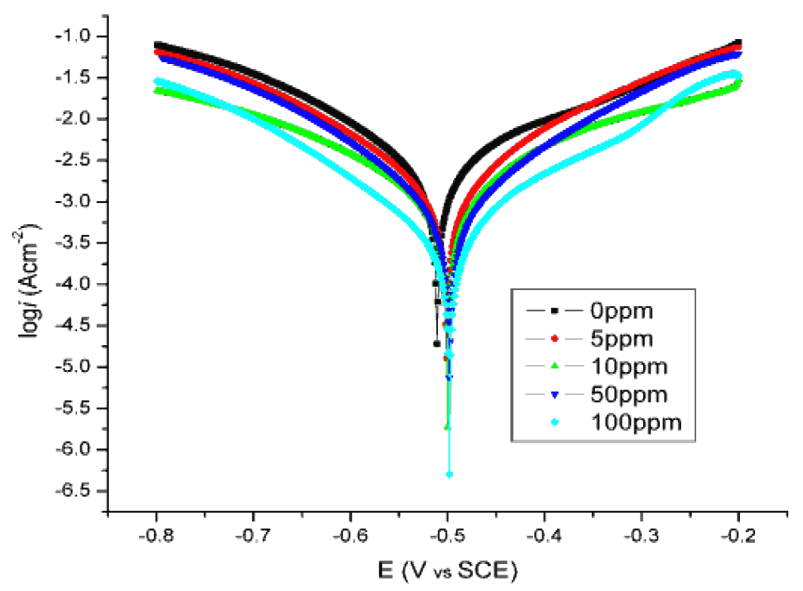

Fig. 2. Potentiodynamic polarization curves of mild steel in $1 \mathrm{M}$ $\mathrm{HCl}$ solution at $303 \mathrm{~K}$ containing various concentrations of inhibitor.

Table 1. Electrochemical parameters of mild steel in $1 \mathrm{M} \mathrm{HCl}$ solution at $303 \mathrm{~K}$ by polarization method

\begin{tabular}{ccccccc}
\hline$[$ inhibitor $] / \mathrm{ppm}$ & $i_{\text {corr }} \times 10^{-3}(\mathrm{~A})$ & $\mathrm{C} . \mathrm{R} \times 10^{2}(\mathrm{mil} / \mathrm{year})$ & $E_{\text {corr }}(\mathrm{V})$ & $\beta \mathrm{a}(\mathrm{V} / \mathrm{dec})$ & $\beta \mathrm{c}(\mathrm{V} / \mathrm{dec})$ & $\mathrm{I} . \mathrm{E}(\%)$ \\
\hline 0 & 2.81 & 13.2 & -0.5105 & 5.106 & 7.357 & -- \\
5 & 1.29 & 5.929 & -0.5009 & 7.757 & 7.696 & 53.77 \\
10 & 1.09 & 5.066 & -0.4996 & 6.528 & 6.403 & 61.2 \\
50 & 0.72 & 3.287 & -0.4996 & 8.446 & 8.457 & 74.38 \\
100 & 0.42 & 1.918 & -0.4981 & 6.81 & 8.23 & 85.04 \\
\hline
\end{tabular}


cathodic process is the discharge of hydrogen ions to produce hydrogen molecules or reduction of oxygen. The inhibitor may affect either of them or both anodic and cathodic process.

The decrease in $i_{\text {corr }}$ with increase in inhibitor concentration was associated with shift in the corrosion potential $\left(E_{c o r r}\right)$ towards less negative values, indicating suppression of anodic reaction. Ferreira et al. ${ }^{19}$ and Li et al. ${ }^{20}$ proposed that for an inhibitor to be considered as cathodic or anodic type the minimum shift in corrosion potential ( $E_{\text {corr }}$ ) should be $\pm 85 \mathrm{mV}$. In the present study the maximum displacement in corrosion potential $\left(E_{\text {corr }}\right)$ is found to be $12 \mathrm{mV}$ which indicates mixed type of inhibition. This suggests that inhibitor gets adsorbed on the steel surface and retards both anodic and cathodic reactions thereby decreasing the rate of corrosion.

\section{Electrochemical impedance spectroscopic measure- ments (EIS)}

The impedance spectra (Nyquist plots) of mild steel in $1 \mathrm{M} \mathrm{HCl}$ containing 5, 10, 50, $100 \mathrm{ppm}$ of nevirapine at $303 \mathrm{~K}$ is shown in Fig. 3. Nyquist plot contains depressed semicircle with centre under real axis. The size of the semicircle increases with the inhibitor concentration, indicating the charge transfer process as the main controlling factor for the corrosion inhibtion of mild steel. It is apparent from the figure that, shapes of the impedance plots for inhibited specimen are not substantially different from those of uninhibited one's and the impedance of the inhibited solution has increased with the increase in the concentration of the inhibitor, indicating that inhibitor does not alter the mechanism of electrochemical reactions

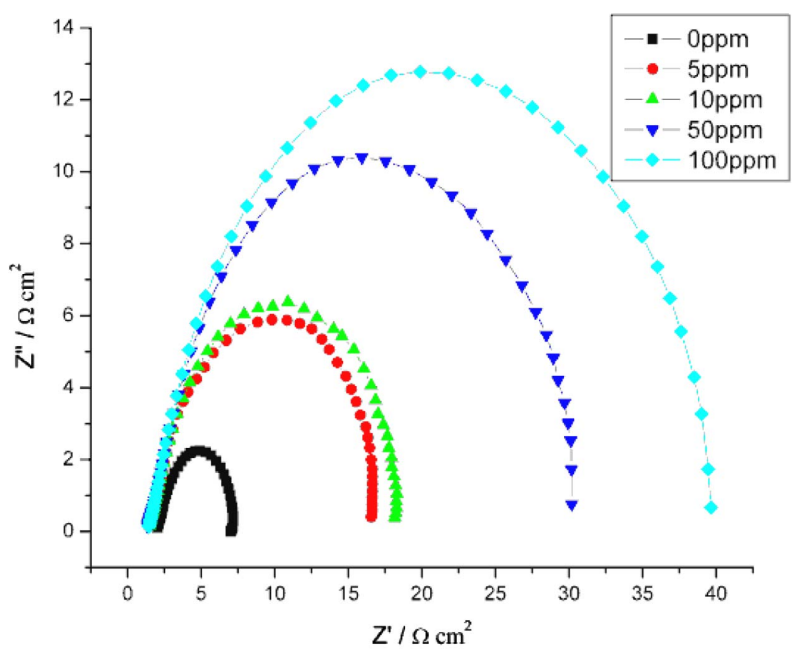

Fig. 3. Nyquist plots for mild steel in $1 \mathrm{M} \mathrm{HCl}$ solution at $303 \mathrm{~K}$ containing various concentrations of inhibitor.
Table 2. AC impedance data of mild steel in $1 \mathrm{M} \mathrm{HCl}$ solution at $303 \mathrm{~K}$

\begin{tabular}{cccc}
\hline [inhibitor] $/ \mathrm{ppm}$ & $R_{p}\left(\Omega \mathrm{cm}^{2}\right)$ & $\mathrm{I} . \mathrm{E}(\%)$ & $C_{d l}\left(\mu \mathrm{Fcm}{ }^{2}\right)$ \\
\hline 0 & 7.17 & - & 318.4 \\
5 & 16.55 & 56.67 & 249.9 \\
10 & 18.32 & 60.86 & 238.7 \\
50 & 30.25 & 76.29 & 216.1 \\
100 & 39.48 & 81.83 & 184.1 \\
\hline
\end{tabular}

responsible for corrosion and inhibits corrosion primarily through its adsorption on the metal surface. ${ }^{21}$ This indicates that the inhibitive action of inhibitor occurs by blocking the available surface area for corrosion.

The experimental result of EIS measurements for the corrosion of mild steel in $1 \mathrm{M} \mathrm{HCl}$ in the absence and presence of the inhibitor is given in Table 2. As it can be observed from the table, the polarization resistance $\left(R_{p}\right)$ value increased with increase in the concentration of the inhibitor. Whereas values of the capacitance of the interface $\left(C_{d l}\right)$ starts decreasing, with increase in inhibitor concentration, which is most probably due to the decrease in local dielectric constant and/or increase in thickness of the electrical double layer. This suggests that the inhibitor acts via adsorption at the metal/solution interface ${ }^{22}$ and the decrease in the $C_{d l}$ values is caused by the gradual replacement of water molecules by the adsorption of the inhibitor molecules on the electrode surface, which decreases the extent of metal dissolution. ${ }^{23}$

The inhibition efficiency is given by: ${ }^{24}$

$$
\% \text { I.E }\left(R_{p}\right)=\frac{R_{p(\text { inhi })}-R_{p}}{R_{p(\text { inh })}} \times 100
$$

where $R_{p}$ is polarization resistance without inhibitor, and $R_{p(i n h i)}$ is polarization resistance with inhibitor.

$C_{d l}$ value is obtained from the equation (3):

$$
2 \pi f_{\max }=\frac{1}{R_{p} c_{d l}}
$$

where, $f_{\max }$ is the frequency at the top of the semicircle (where- $Z$ " is maximum).

\section{Weight loss measurements}

To elucidate the mechanism of inhibition and to determine the thermodynamic parameters of the corrosion process weight loss measurements were performed at 303, $313,323,333 \mathrm{~K}$. The corrosion rate $\left(C_{R}\right)$ in mils penetration per year (MPY) is calculated using the formula,

$$
C_{R}=\frac{534 \mathrm{~W}}{\mathrm{DAT}}
$$


Table 3. Corrosion parameters for mild steel in $1 \mathrm{M} \mathrm{HCl}$ in the absence and presence of different concentrations of the inhibitor at different temperature

\begin{tabular}{ccccccccc}
\hline $\begin{array}{c}{[\text { Inhibitor }]} \\
(\mathrm{ppm})\end{array}$ & \multicolumn{4}{c}{ Wt Loss $\left(\mathrm{mg} / \mathrm{cm}^{2}\right)$} \\
\cline { 2 - 9 } & $303 \mathrm{~K}$ & $313 \mathrm{~K}$ & $323 \mathrm{~K}$ & $338 \mathrm{~K}$ & $303 \mathrm{~K}$ & $313 \mathrm{~K}$ & $323 \mathrm{~K}$ & $338 \mathrm{~K}$ \\
\hline 0 & 127.5 & 202.2 & 300.1 & 480.8 & - & - & - & - \\
5 & 55.70 & 86.68 & 126.1 & 198.19 & 56.32 & 57.13 & 57.98 & 58.78 \\
10 & 46.52 & 72.17 & 104.7 & 163.57 & 63.52 & 64.31 & 65.12 & 65.98 \\
50 & 28.81 & 44.65 & 65.07 & 100.39 & 77.41 & 77.92 & 78.32 & 79.12 \\
100 & 17.88 & 27.42 & 38.62 & 56.35 & 85.98 & 86.44 & 87.13 & 88.28 \\
\hline
\end{tabular}

where, $W$ is weight loss in milligrams, $D$ is density in grams per cubic centimeter, $A$ is area in square inches, $T$ is time in hours.

The I.E(\%) was calculated using the following equation (5).

$$
\operatorname{I.E}(\%)=\frac{W_{2}-W_{1}}{W_{1}} \times 100
$$

where $W_{1}$ and $W_{2}$ are weight loss of mild steel in the presence and absence of the inhibitor. The weight loss results of mild steel in $1 \mathrm{M} \mathrm{HCl}$ in the absence and presence of various concentrations of the inhibitor at different temperatures are summarized in Table 3. The inhibition efficiency increased with increase in the concentration of the inhibitor for mild steel in $1 \mathrm{M} \mathrm{HCl}$. The slight increase in the inhibition efficiency for corrosion of mild steel at higher temperature can be attributed to the occurrence of chemical adsorption of the inhibitor molecules on its surface.

\section{Thermodynamic parameters}

The apparent activation energy $\left(E_{a}^{o}\right)$ of metal corrosion in acid media can be calculated from the Arrhenius equation. $^{25}$

$$
\ln C_{R}=\frac{E_{a}^{o}}{R T}+\mathrm{A}
$$

where $E_{a}^{o}$ is the apparent activation energy for the corrosion of mild steel, $\mathrm{R}$ is the universal gas constant, $\mathrm{A}$ is Arrhenius pre exponential factor and $\mathrm{T}$ is the absolute temperature. The values of $E_{a}^{o}$ obtained from the slope of the $\log C_{R}$ vs 1/T plot (Fig. 4) are given in Table 4.

The relationship between the temperature dependence of inhibition efficiency of an inhibitor and the activation energy found in its presence was given as follows: ${ }^{26}$

(i) Inhibitors whose inhibition efficiency decreases with temperature increase. The value of activation energy $\left(E_{a}^{o}\right)$ found is greater than that in the uninhibited solution.

(ii) Inhibitors whose inhibition efficiency does not change

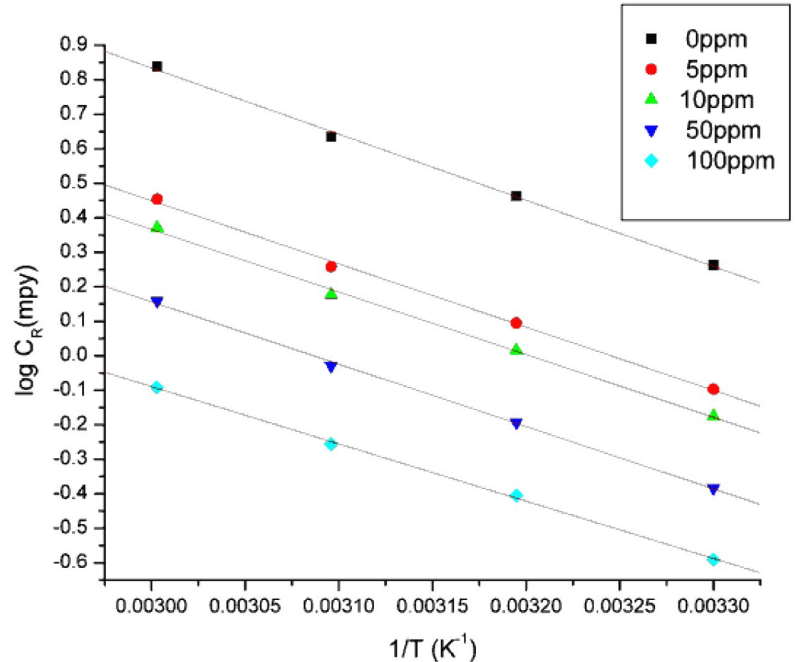

Fig. 4. Arrhenius plot for mild steel in $1 \mathrm{M} \mathrm{HCl}$ solution in the absence and presence of different concentrations of the inhibitor.

Table 4. Values of activation parameters $E_{a}^{o}, \Delta S_{a}^{o}, \Delta H_{a}^{o}$ for mild steel in $1 \mathrm{M} \mathrm{HCl}$ in the absence and presence of different concentrations of the inhibitor

\begin{tabular}{ccccc}
\hline $\begin{array}{c}\text { Temperature } \\
(\mathrm{K})\end{array}$ & $\begin{array}{c}\mathrm{K} \\
\left(\mathrm{mol}^{-1}\right)\end{array}$ & $\begin{array}{c}\Delta G_{a d s}^{o} \\
\left(\mathrm{kJmol}^{-1}\right)\end{array}$ & $\begin{array}{c}\Delta H_{a d s}^{o} \\
\left(\mathrm{kJmol}^{-1}\right)\end{array}$ & $\begin{array}{c}\Delta S_{a d s}^{o} \\
\left(\mathrm{Jmol}^{-1}\right)\end{array}$ \\
\hline 303 & 56635.22 & -37.6 & & \\
313 & 58263.77 & -37.7 & -36.4947 & 4.04 \\
323 & 59108.59 & -37.7 & & \\
333 & 59455.76 & -37.8 & & \\
\hline
\end{tabular}

with temperature variation. The value of activation energy $\left(E_{a}^{o}\right)$ does not change with the presence or absence of inhibitors.

(iii) Inhibitors whose inhibition efficiency increases with temperature increase. The value of activation energy $\left(E_{a}^{o}\right)$ found is less than that in the uninhibited solution.

The higher value of activation energy $\left(E_{a}^{o}\right)$ in the presence of inhibitor than in its absence is attributed to its physical adsorption, its chemisorptions is, ${ }^{27}$ while pronounced in the opposite case. ${ }^{7}$

In the present study the lower value of $E_{a}^{o}$ for mild steel in an inhibitor's presence, compared to that in its absence 
indicates the formation of chemisorbed mono layer. The decrease in activation energy of corrosion at higher levels of inhibition arises from a shift of the net corrosion reaction from that on the uncovered part on the metal surface to the covered one.

An alternative form of Arrhenius equation is the transition state equation ${ }^{24}$ which is given as,

$$
C_{R}=\frac{R T}{N h} \exp \left(\frac{\Delta S_{a}^{o}}{R}\right) \exp \left(-\frac{\Delta H_{a}^{o}}{R T}\right)
$$

where, $\mathrm{h}$ is the Plank's constant, $\mathrm{N}$ is the Avogadro's number, $\Delta S_{a}^{o}$ is the entropy of activation, and $\Delta E_{a}^{o}$ is the enthalpy of activation. A plot of $\log \left(\mathrm{C}_{\mathrm{R}} / \mathrm{T}\right)$ vs $1 / \mathrm{T}$ gave a straight line (Fig. 5) with a slope of $\left(-\Delta E_{a}^{o} / 2.303 \mathrm{R}\right)$ and an intercept of $\left[\log (\mathrm{R} / \mathrm{Nh})+\left(\Delta S_{a}^{o} / \mathrm{R}\right)\right]$, from which the values of $\Delta E_{a}^{o}$ and $\Delta S_{a}^{o}$ were calculated and listed in Table 4.

The positive values of $\Delta E_{a}^{o}$ for corrosion of mild steel in the presence and absence of the inhibitor reflect the endothermic nature of metal dissolution process. The decrease in $\Delta H_{a}^{o}$ with increase in inhibitor concentration for mild steel corrosion reflected that decrease in corrosion rate is chiefly decided by the pre-exponential factor. ${ }^{28}$

The negative increment in $\Delta S_{a}^{o}$ with increase in the concentration of the inhibitor reveals that decrease in randomness takes place on going from reactant to the activated complex. $^{29}$ This reflects the formation of an ordered stable film of inhibitor on mild steel surface. ${ }^{30}$

\section{Adsorption Isotherms}

In order to understand the mechanism of corrosion inhibition, the adsorption behavior of the organic adsorbate on

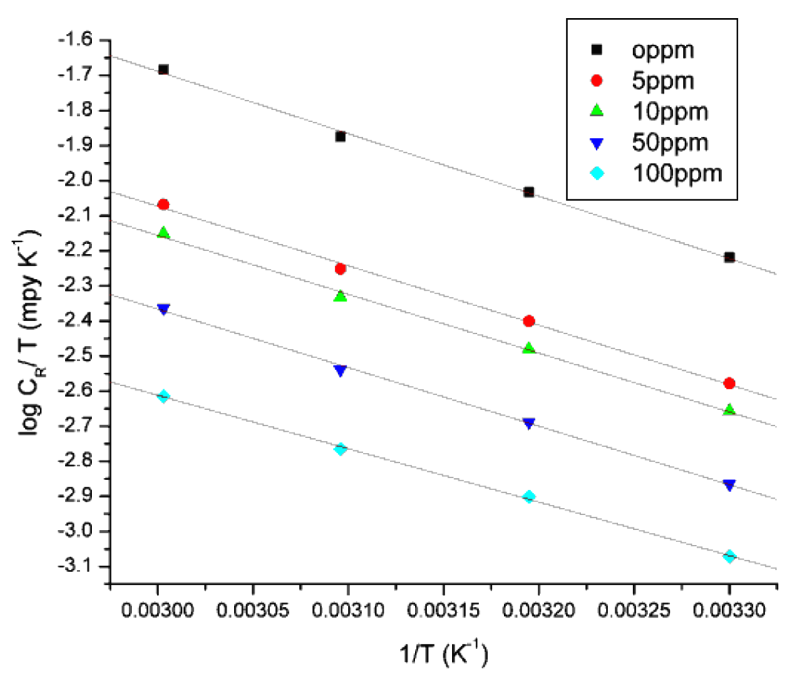

Fig. 5. Transition plot for mild steel in $1 \mathrm{M} \mathrm{HCl}$ solution in the absence and presence of different concentrations of the inhibitor.

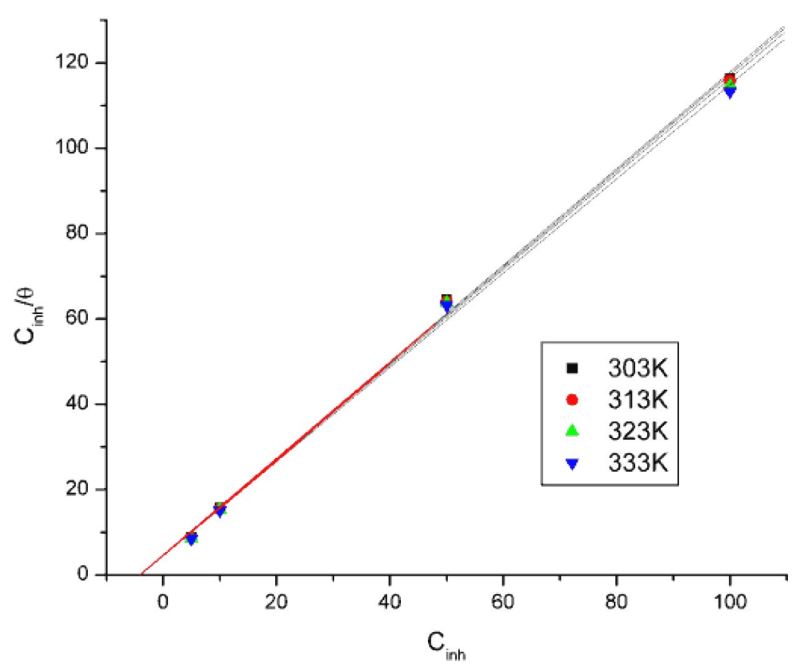

Fig. 6. Langmuir adsorption isotherm for mild steel in $1 \mathrm{M} \mathrm{HCl}$ solution at $303 \mathrm{~K}$.

the metal surface has to be known. The degree of surface coverage $(\theta)$ for different concentration of the inhibitor $\left(C_{\text {inhi }}\right)$ has been evaluated. The data were tested graphically by fitting to various isotherms. A straight line with correlation coefficient nearly equal to 1.0 was obtained on plotting $C_{i n h i} / \theta$ against $C_{i n h i}$ suggesting adsorption of the compound on the mild steel surface followed Langmuir adsorption isotherm model (Fig. 6) at all studied temperatures. According to this isotherm, the surface coverage $(\theta)$ is related to inhibitor concentration $C_{i n h}{ }^{31}$ by,

$$
\frac{C_{i n h i}}{\theta}=\frac{1}{K_{a d s}}+C
$$

where, $K_{a d s}$ is equilibrium constant of the equilibrium adsorption process. This isotherm assumes that adsorbed molecules occupy only one site and it does not interact with other adsorbed species. The $K_{a d s}$ values can be calculated from the intercept lines on the $C_{\text {inhi }} / \theta$ axis. This is related to the standard free energy of adsorption $\left(G_{a d s}\right)$ by the following equation:

$$
\Delta G_{a d s}^{o}=-\mathrm{RT} \ln \left(55.5 K_{a d s}\right)
$$

where, $R$ is the gas constant and $\mathrm{T}$ is the absolute temperature. The constant value of 55.5 is the concentration of water in solution in $\mathrm{mol} / \mathrm{L}$. The calculated values of $K_{a d s}$ and $\Delta G_{a d s}^{o}$ are given in Table 5.

Generally, the magnitude of $\Delta G_{a d s}^{o}$ around $-20 \mathrm{~kJ} / \mathrm{mol}$ or less negative indicates electrostatic interactions between inhibitor and the charged metal surface (i.e., physisorption). Those around $-40 \mathrm{~kJ} / \mathrm{mol}$ or more negative are indic- 
Table 5. Values of thermodynamic parameters for the adsorption of the inhibitor in $1 \mathrm{M} \mathrm{HCl}$ on the mild steel at different temperatures

\begin{tabular}{cccc}
\hline [inhibitor] $/ \mathrm{ppm}$ & $E_{a}^{o}\left(\mathrm{kJmol}^{-1}\right)$ & $\Delta E_{a}^{o}\left(\mathrm{kJmol}^{-1}\right)$ & $\Delta S_{a}^{o}\left(\mathrm{Jmol}^{-1}\right)$ \\
\hline 0 & 36.7 & 34.1 & -127.5 \\
10 & 35.1 & 32.4 & -139.8 \\
50 & 34.7 & 32.1 & -142.3 \\
100 & 34.5 & 31.9 & -146.9 \\
200 & 31.8 & 29.1 & -160.0 \\
\hline
\end{tabular}

ative of charge sharing or transferring from organic species to the metal surface to form a coordinate type of metal bond (i.e., chemisorptions). In the present work, the calculated values of $\Delta G_{a d s}^{o}$ at $303 \mathrm{~K}$ for mild steel is $-37 \mathrm{~kJ} / \mathrm{mol}$, which indicated that adsorption of the inhibitor on the metal surface involves complex interactions: both physical and chemical process. ${ }^{32,34}$ The negative value of $\Delta G_{\text {ads }}^{o}$ indicated spontaneous adsorption of the inhibitor on the metal surface. The slight increase in $K_{a d s}$ with increase in temperature indicated increased adsorption with increase in temperature which is attributed to the occurrence of chemical adsorption.

The enthalpy of adsorption $\left(\Delta H_{a d s}^{o}\right.$ can be calculated from the Gibbs-Helmholtz equation:

$$
\Delta G_{a d s}^{o}=\Delta H_{a d s}^{o}-\mathrm{T} \Delta S_{a d s}^{o}
$$

The plot of $\Delta G_{a d s}^{o}$ versus $\mathrm{T}$ gives a straight line with the slope equal to - $\Delta S_{a d s}^{o}$ and the value of $\Delta H_{a d s}^{o}$ can be calculated from the intercept of the line. The negative sign of $\Delta H_{a d s}^{o}$ indicated the exothermic process of adsorption of inhibitor on mild steel. The positive value of $\Delta G_{a d s}^{o}$ in the presence of inhibitor is an indication of increase in solvent entropy. The increase in disorder is attributed to the desorption of more water molecules from the metal surface by one inhibitor molecule. Therefore it is revealed that decrease in the enthalpy is the driving force for the adsorption of the inhibitor on the surface of the steel. ${ }^{35-37}$

\section{Mechanism of Corrosion Inhibition}

In acid medium nevirapine gets protonated at nitrogen atoms of the pyridine ring, which results in the formation of positively charged inhibitor species as follows:

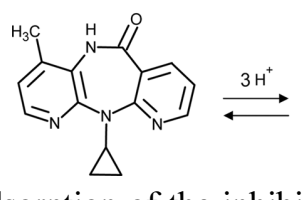<smiles></smiles>

Thus adsorption of the inhibitor on the mild steel surface may occur through the following ways (Fig. 7):

i) The electronic configuration of $\mathrm{Fe}$ is $[\mathrm{Ar}] 3 \mathrm{~d}^{6} 4 \mathrm{~s}^{2}$.

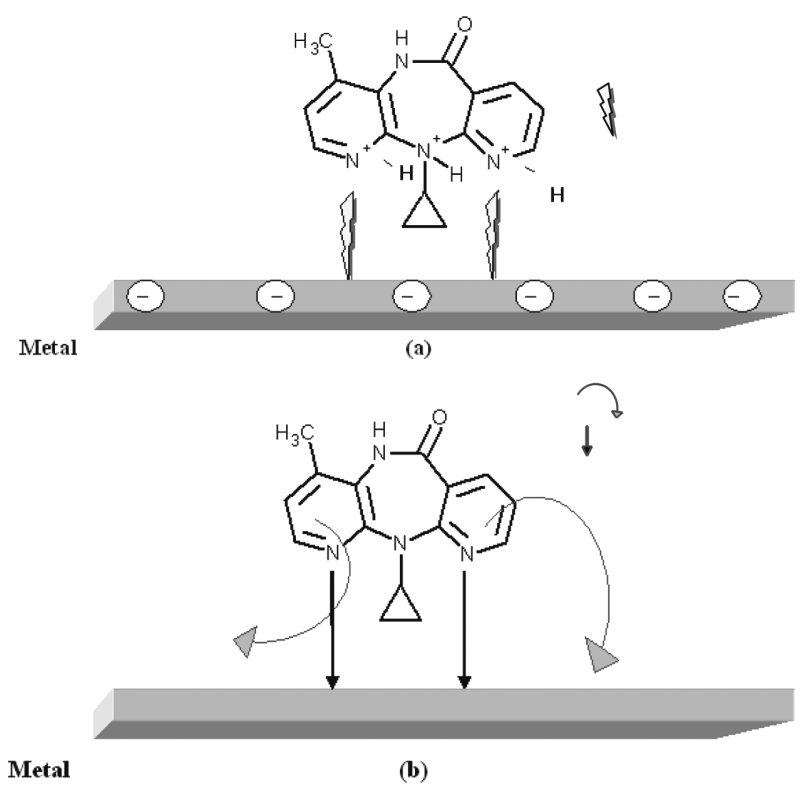

Fig. 7. Adsorption of Nevirapine on the mild steel surface (a) electrostatic interaction (b) $\mathrm{e}^{-}$pair interaction.

Thus, vacant $3 \mathrm{~d}$ orbitals of iron can bond with inhibitor due to interaction of electron rich $\pi$ - electron clouds of aromatic ring as well as unshared electron pairs on nitrogen atom of the inhibitor.

ii) The protonated inhibitor could be attached to the steel surface which is negatively charged in hydrochloric acid medium due to the specifically adsorbed $\mathrm{Cl}^{-}$ions on the metal surface. Thus adsorption can occur via electrostatic interaction between positively charged inhibitor molecules and negatively charged metal surface.,20

The increase in the inhibition efficiency with increase in temperature suggests that adsorption of the inhibitor occurs mainly by chemisorption involving interaction of vacant d-orbital of iron with lone pair of electrons on nitrogen as well as $\pi$ - electron clouds of the inhibitor.

\section{CONCLUSION}

1) Nevirapine is a good inhibitor for the corrosion of mild steel in $1 \mathrm{M} \mathrm{HCl}$ and inhibition efficiency was more pronounced with increase in the inhibitor concentration.

2) The results obtained from polarization, impedance techniques and weight loss measurements are in good agreement.

3) The potentiodynamic polarization curves imply that, the corrosion inhibition by nevirapine for mild steel in $1 \mathrm{M}$ $\mathrm{HCl}$ is due to the suppression of anodic reaction.

4) The inhibition efficiency of the inhibitor slightly 
increased with temperature for corrosion of mild steel.

5) The adsorption of inhibitor on the surface of mild steel obeys Langmuir adsorption isotherm.

Acknowledgement. Authors thank Dr. Arthoba Naik and Dr. Basavanna of Kuvempu University for their help and support.

\section{REFERENCES}

1. Ramesh Saliyan, V.; Vasudeva Adhikari, A. Corros. Sci. 2008, 50, 55.

2. Bastidas, J. M.; Polo, J. L.; Cano, E. J. Appl. Electrochem. 2000, 10, 1173.

3. Jyotsna Shukla; Pitre, K. S. Bull. Electrochem. 2004, 20, 309.

4. Bereket, G.; Ogretir, C.; Yurt, A. J. Mol. Struct. 2001, $571,139$.

5. Tianbao, D. U.; Jiajian Chen; Dianzhen Cao. J. Mater. Sci. 2001, 36, 3903.

6. Branzoi, V.; Florentian Golgovici; Florina Branzoi. Mater. Chem. Phys. 2003, 78, 122.

7. Obot, I. B.; Obi-Egbedi, N. O.; Umoren, S. A. Corros. Sci. 2009, 51, 1868.

8. Zerfaoui, M.; Oudda, H.; Hammouti, B.; Kertit, S. Prog. Org. Coat. 2004, 51, 134.

9. Mohamed Awad K. J. Electroanal. Chem. 2004, 567, 219.

10. Solmaz, R.; Kardas, G.; Culha, M.; Yazici, B.; Erbil, M. Electrochim. Acta 2008, 53, 5941.

11. Tamil Selvi, S.; Raman, V.; Rajendran, N. J. Appl. Electrochem. 2003, 33, 1175.

12. Abdallah, M. Corros. Sci. 2004, 46, 1981.

13. Imran, N.; Saleemi, A. R.; Naveed, S. Int. J. Electrochem. Sci. 2011, 6, 146.

14. Fouda, A. S.; Mostafa, H. A.; El-Abbasy, H. M. J. Appl. Electrochem. 2010, 40, 163.

15. Obot, I. B.; Obi-Egbedi, N. O.; Umoren, S. A. Int. J. Electrochem. Sci. 2009, 4, 863.
16. Montaner, J. S.; Reiss, P.; Cooper, D. J. Am. Med. Ass. 1998, 279, 930.

17. Conway, B.; Wainberg, M. A.; Hall, D. AIDS. 2001, 15, 1269.

18. Emrgul, K. C.; Akay, A. A.; Atakol, O. Mater. Chem. Phys. 2005, 93, 325.

19. Ferreira, E. S.; Giancomelli, C.; Giancomelli, F. C.; Sinelli, A. Mater. Chem. Phys. 2004, 83, 129.

20. Li, W. H.; He, Q.; Zhang, S. T.; Pei, C. L.; Hou, B. R. J. Appl. Electrochem. 2008, 38, 289.

21. Poornima, T.; Jagannath Nayak; Nityananda Shetty, A. Appl. Electrochem. 2011, 41, 223.

22. Khaled, K. F. Electrochim. Acta 2003, 48, 2493.

23. Aljourani, J.; Raeissi, K.; Golozar, M. A. Corros. Sci. 2009, 51, 1836.

24. Cruz, J.; Martinez, R.; Genesca, J.; Garcia-Ochoa, E. J. Electroanal. Chem. 2004, 566, 111.

25. Zhang, Q. B.; Hua, Y. X. Mater. Chem. Phys. 2010, 119, 57.

26. Dehri, I.; Ozcan, M. Mater. Chem. Phys. 2006, 98, 316.

27. Szauer, T.; Brand, A. Electrochim. Acta 1981, 26, 1253.

28. Bouklah, M.; Hammouti, B.; Lagrenee, M.; Bentiss, F. Corros. Sci. 2006, 48, 2831.

29. Quraishi, M. A; Rafiquee, M. Z. A.; Khan, S.; Saxena, N. J. Appl. Electrochem. 2007, 37, 1153.

30. Bentiss, F.; Lebrini, M.; Lagrenee, M. Corros. Sci. 2005, 47, 2915.

31. Li, X. H.; Deng, S. D.; Mu, G. N.; Fu, H.; Yang, F. Z. Corros. Sci. 2008, 50, 420.

32. Ashish Kumar Singh; Quraishi, M. A. Corros Sci. 2010, $52,152$.

33. Bouklah, M.; Benchat, N.; Hammouti, B.; Aouniti, A.; Kertit, S. Mater. Lett. 2006, 60, 1901.

34. Geler, E.; Azambuja, D. S. Corros. Sci. 2000, 42, 631.

35. Ashish Kumar Singh; Quraishi, M. A. Corros. Sci. 2010 , 52, 1373.

36. Gulsen Avci. Coll. Surf. 2008, 317, 730.

37. Xianghong Li; Shudan Deng; Hui Fu; Guannan Mu. Corros Sci. 2009, 51, 620. 